\title{
Tersine Mühendisliğin Makine Mühendisliği Alanındaki Uygulamaları Üzerine Bir Derleme
}

\author{
Ahmet Hasçelik ${ }^{1 *}$

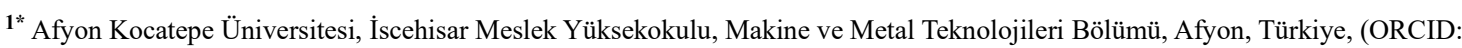 \\ 0000-0002-4615-0640), ahascelik@aku.edu.tr
}

(İlk Geliş Tarihi 24.12.2021 ve Kabul Tarihi 31.12.2021)

(DOI: 10.29228/JCHAR.55624)

ATIF: Tersine Mühendisliğin Makine Mühendisliği Alanındaki Uygulamaları Üzerine Bir Derleme. Journal of Characterization, (1), Özel sayı, 42-53, 2021.

\begin{abstract}
Öz
Tersine mühendislik, bir parçanın üretim sürecini geriye doğru gerçekleştirme işlemidir. Tersine mühendisliğin amacı, mevcut bir bilgisayar destekli tasarım (BDT) modeli olmadan, üç boyutlu (3B) model oluşturmaktır. Tersine mühendislik, üreticinin herhangi bir ürünle ilgili eksik dokümantasyona sahip olduğu durumlarda başvurduğu bir süreçtir. Mevcut bir üründen, BDT modelinin elde edilmesi için gerekli bir aşamadır. $\mathrm{Bu}$ çalışmada tersine mühendislik aşamaları anlatılmış ve makine mühendisliği alanındaki uygulamalarından bahsedilmiştir. Literatürdeki çalışmalar incelenmiş ve bu alandaki çalışmalar derlenmiştir. $\mathrm{Bu}$ alanda sıklıkla karşılaşılan birkaç tersine mühendislik işlemi ile ilgili detaylı bilgi verilmiştir. Çalışmada genel olarak tersine mühendislik sürecinin anlaşılması hedeflenmiş ve özellikle makine mühendisliği alanında, hangi durumlarda tersine mühendislik işlemine başvurulduğunun tespiti üzerinde durulmuştur. Böylece tersine mühendislik sürecinin makine sektöründe oldukça pratik ve verimli bir seçenek olduğu vurgulanmıştır.
\end{abstract}

Anahtar Kelimeler: Tersine Mühendislik; Makine Mühendisliği; Bilgisayar Destekli Tasarım; Hızlı Prototipleme; Optik Tarama; Üç Boyutlu Model.

\section{A Review on the Applications of Reverse Enginnering in the Mechanical Enginnering}

\begin{abstract}
Reverse engineering is the process of performing the manufacturing process of a part backwards. The goal of reverse engineering is to create a three-dimensional (3D) model without an existing computer aided design (CAD) model. Reverse engineering is a process that a manufacturer resorts to when they have missing documentation for any product. It is a necessary step to obtain a CAD model from an existing product. In this study, reverse engineering stages are explained and its applications in the field of mechanical engineering are mentioned. Studies in the literature were examined and compiled. Detailed information is given about a few reverse engineering processes that are frequently encountered in this field. The aim of this study is to understand the reverse engineering process in general and. especially in the field
\end{abstract}


of mechanical engineering, it has been focused on the determination of the situations in which reverse engineering is applied. Thus, it is emphasized that the reverse engineering process is a very practical and efficient option in the machinery industry.

Keywords: Reverse Engineering; Mechanical Engineering; Computer Aided Design; Rapid Prototyping; Optical Scanning; Three Dimensional Model.

\section{Giriş}

Mühendislik, insanlığın ihtiyaçları doğrultusunda, tasarlanan bir yapı, sistem ya da ürünün, matematik ve fen bilimlerine ilişkin bilgiler kullanılarak üretimini ve akabinde devamlılığını sağlayan, zaman ve verimi artırmaya yönelik değerlendirmeler yaparak bunları uygulamaya döken bir bilimdir. Mühendisliği en geniş kapsamda, ileriye dönük (forward) mühendislik ve geriye dönük (reverse) mühendislik olarak ikiye ayırabiliriz [1].

İleriye dönük mühendislik kavramı, geniş anlamdaki mühendislik uygulamaları süreçlerini kapsar. Örneğin makine mühendisliği alanında bir ürün imalatı sürecini inceleyecek olursak; bu süreç, öncelikle fikir olarak ihtiyaç doğrultusunda bir ürün tasarımı ile başlar, malzeme seçiminden sonra gerekli mühendislik hesaplamaları yapılır ve tasarım süreci tamamlanır. Tasarım süreci; teknik veriler, çizimler ve model üretimi gibi aşamaları kapsar. Kullanılacak üretim yöntemi seçildikten sonra uygulamaya geçilir. Bazı durumlarda, klasik mühendislik işlemindeki bu süreçlerden birkaçı eksik olabilir. Örneğin üreticide, mevcut ürünü seri üretimle çoğaltmak için gerekli teknik resim veya tasarım modeli olmayabilir [2]. Buna benzer durumlarda ürünün kendisinden hareket ederek üretim sürecini geriye doğru gerçekleştirme işlemi yapılır. Böylece ürünün başlangıç aşamasındaki teknik bilgileri elde edilir. Bu şekilde geriye giderek, ürünün başlangıçtaki bilgisayar destekli tasarım modelini elde etme işlemine Tersine Mühendislik (Reverse Engineering) denir [1], [3].

Tersine mühendislik ihtiyacı; üreticinin uzun zamandır üretmediği bir parçayı yeniden üretmek istemesi, orijinal tasarımın yeterli veriye sahip olmaması, mevcut bir ürün üzerinde revizyon yapılmak istenmesi, rakip ürünlerin analiz edilmesi, ürün performansını artıracak yeni yollar aranması, orijinal bilgisayar destekli tasarım modelinin yeterli olmaması, yedek parça temin etmekte meydana gelebilecek sıkıntılar ya da eski üretim işlemlerinin günümüz teknolojisi ile güncellenerek daha ucuza mal edilmek istenmesi gibi durumlarda ortaya çıkabilir [4], [7].

Tersine mühendisliğin amacı, mevcut bir BDT modeli olmadan, 3b model oluşturmaktır [14]. Bu modelin oluşturulması için birkaç aşama gereklidir. Şekil 1'de, tersine mühendislik süreci ile ilgili temel bir diyagram gösterilmiştir.

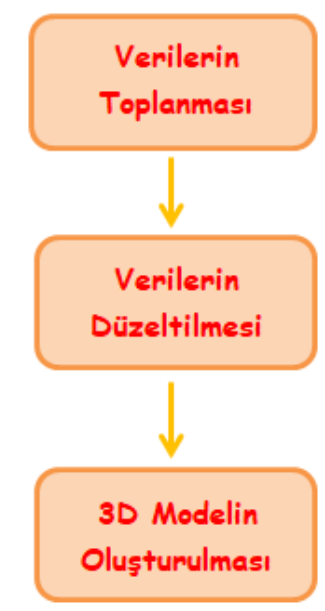

Şekil 1. Tersine mühendislikte izlenilen yol.

Şekil ve özellik bakımından farklı nesnelerin 3b modelinin oluşturulması için kullanılan makine görüş sistemleri, verilerin toplanması amacıyla görüntü verileri üzerinde çalışır. Verileri toplama işlemi; lazer radar, lazer tarama teknikleri ve nokta detektörleri ile gerçekleştirilir. Tarama işlemi boyunca yüzey üzerinde hareket eden sayısal tarama sustası, nokta bulutu matrisini oluşturur. Sayısallaştırma işlemi olarak da tanımlanan bu kısımda kullanılan cihazlar iki ana grup altında incelenebilir (Şekil 2) [1], [9]. 
Temas ederek (Problu) ölçüm yapan cihazlarda, ölçüm kolunun üzerinde bir küre mevcuttur. Bu küre, iş parçasının yüzeyine temas ettirilerek, iş parçasının geometrik ve boyutsal verileri üç boyutlu $(\mathrm{x}, \mathrm{y}, \mathrm{z})$ olarak elde edilir ve bilgisayar ortamına aktarılır. Ölçüm alınabilmesi için probun yüzeye değme zorunluluğunun bulunması, karmaşık şekle sahip iş parçalarının taranmasında dezavantaj teşkil eder [7]. Temaslı yöntemleri, koordinat ölçüm makineleri (CMM) ve dokunmatik sensöre sahip robotik kollar olarak iki dalda sinıflandırabiliriz. CMM'ler ölçüm yüzeyi üzerindeki belirli bir yolu takip ederek yüksek hassasiyette veri toplayabilirler. Robotik kollar ise, üzerine entegre edilen dokunmatik algılayıcılar sayesinde temas ettiği yüzeylerden hassas veriler alabilecek şekilde programlanabilirler (Şekil 2) [1].

Temassız yöntemlerden biri olan manyetik yöntemde, yüzeye temas eden manyetik alan teknolojisi ile veri toplanır. Akustik yöntemde ise yüzeyden yansıyan ses dalgalarından faydalanılarak veri toplanmaktadır. Optik yöntemler, hızlı veri toplama kapasitesine sahip olmasından dolayı, temaslı yöntemlere göre kıyasla daha sık tercih edilirler. Optik yöntemleri; lazer üçgenleme, uçuş zamanı, interferometre, yapısal ş̧ıklandırma ve stereo analizleri olarak beş ana kategoriye ayırabiliriz (Şekil 2) [1].

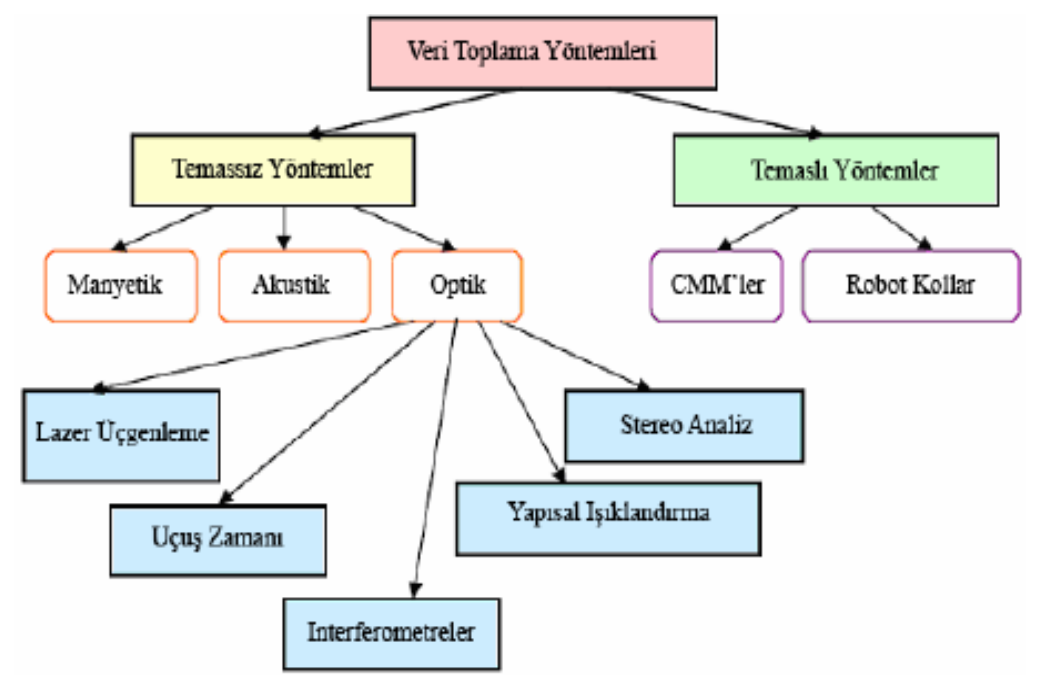

Şekil 2. Tersine mühendislik temel süreç diyagramı [13].

Temassız sistemlerde ölçüm bir lazer hüzmesi kullanılarak ya da topometrik (kameralı) tarama yaparak gerçekleştirilir (Şekil 3). Lazer hüzmesi ile gerçekleştirilen ölçüm, iş parçasının ölçüm yapılmak istenilen bölgelerine gönderilen lazer ışınının kaynaktan gidiş ve dönüş zamanının, ışık hızıyla çarpılması sonucu otomatik olarak hesaplanır. Bu şekilde koordinatlar belirlenir. Lazer ışınının geri dönmesinin söz konusu olamayacağı karmaşık şekle sahip iş parçalarının taranmasındaki güçlüklerden dolayı, bu biçimdeki iş parçaları için önerilen bir yöntem değildir. Topometrik ölçümde ise, iş parçasının yaklaşık 70-100 cm kadar ön tarafına tutulan tarama kafası sayesinde parçanın kenar oluşumlarının izdüşümlerinin yansıması sağlanır. Bu ölçümler kaydedilerek, üç boyutlu koordinatlar hesaplanır [5], [8].

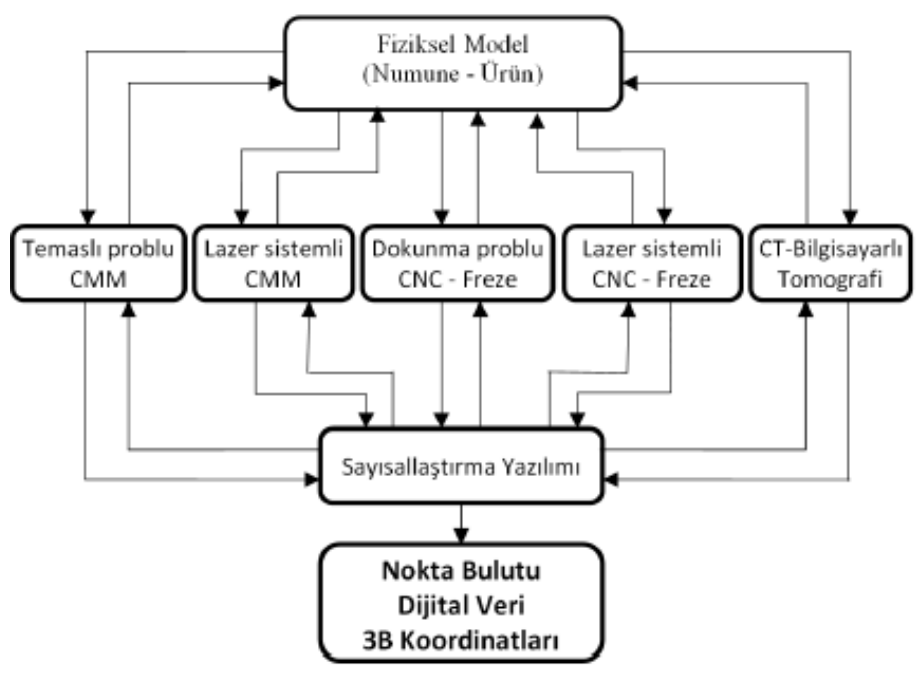


Şekil 3. Ölçüm teknikleri şeması [18].

Temaslı ve temassız veri toplama yöntemlerinde ana hedef, üç boyutlu koordinat sisteminde bir nesnenin sınırlarını belirleyen bir nokta bulutu elde etmektir. Nokta bulutu formatı uygun yazılımlar kullanılarak bilgisayar destekli tasarım ve üretim (BDT/BDÜ) süreçlerine uygun formata (stereolithography-stl) dönüştürülür. Böylelikle nesnenin 3b modeli bilgisayar ortamına aktarılarak model üzerinde istenilen değişiklikler yapılabilir [10], [11]. Model son halini aldıktan sonra, 3b modelden fiziksel yapılar elde edilmesini sağlayan hızlı prototipleme (rapid prototyping) teknolojisi ile üç boyutlu yazıcı kullanılarak üretime geçilebilir. Şekil 4'de tersine mühendislik işlem basamaklarıgösterilmiştir [6].

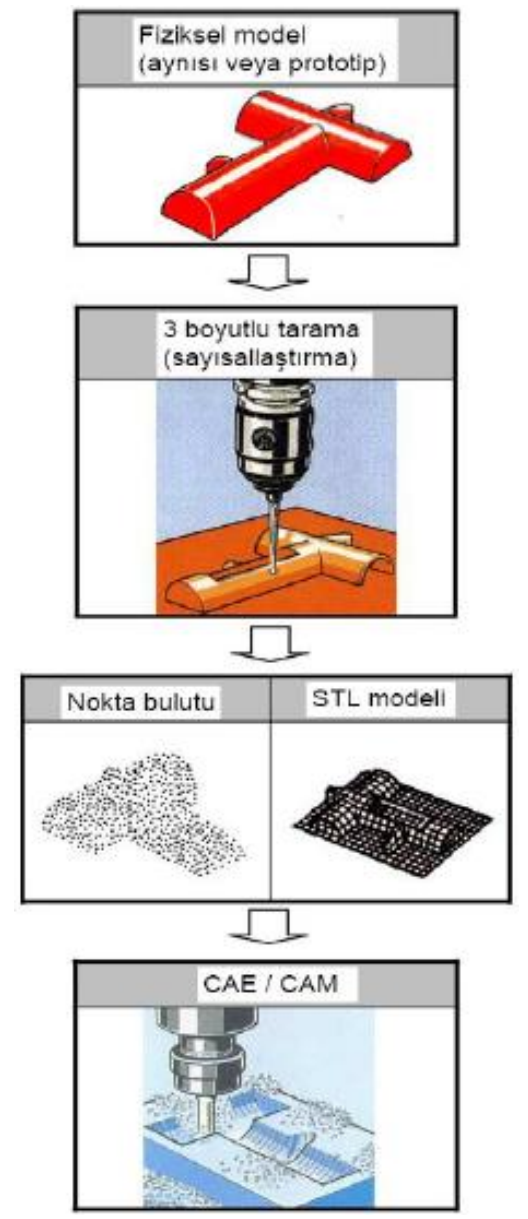

Şekil 4. Tersine mühendislik süreci işlem basamakları [13,18]

$\mathrm{Bu}$ çalışmanın amacı, tersine mühendislik yaklaşımı ile ilgili bilgi vermek, sürecin nasıl işlediğini anlatmak ve makine mühendisliği ile tersine mühendislik arasındaki ilişkiyi irdelemektir. Tersine mühendisliğin makine sektöründeki uygulamalarının nasıl yapıldığı açıklanarak, hangi durumlarda tersine mühendisliğe ihtiyaç duyulduğunun anlaşılması amaçlanmıştır.

\section{Makine ve Malzeme Sektöründe Tersine Mühendislik Çalışmaları}

Tersine mühendisliğin makine mühendisliği alanındaki uygulamaları genellikle parçalarının onarımı üzerine olmaktadır. Deforme olmuş makine elemanları ya da kalıplar, tersine mühendislik teknolojisi kullanılarak yeniden üretilebilmektedir. Ayrıca geliştirilmek istenilen ürünlerin tersine mühendislik uygulamaları ile yeniden BDT modeli elde edilip, ürün revize edilmektedir. Tersine mühendisliğin makine alanındaki bir başka kullanımı ise, seri üretimi yapılmak istenilen bir ürünün BDT modelinin elde edilmesinin amaçlanmasıdır. Üretim aşamasında geriye gidilerek elde edilen BDT modeli, bilgisayar 
destekli üretim (BDÜ) teknolojisi ile yeniden üretilebilmektedir. Literatürde bu amaçlara benzer şekilde birçok tersine mühendislik uygulaması mevcuttur.

Berbercuma [15], türbin çarkını, tersine mühendislik uygulaması ile optik tarayıcıda sayısallaştırıp, nokta bulutu formatında oluşan veriyi $3 \mathrm{~b}$ BDT formatına çevirmiştir. Paulic vd. [16], sac kesme kalıbı üretim sürecini tersine mühendislik ile geriye giderek yeniden incelemişler ve elde ettikleri nokta bulutu verilerini 3b BDT verileri ile karşılaştırmışlardır. Budak vd. [17], karmaşık şekle sahip parçaları kolayca modelleyebilen bir yazılım geliştirmişlerdir. Sokoviç ve Kopac [18], BDT modeli mevcut olmayan ürünlerde tersine mühendislik yöntemlerinin faydalarını incelemişlerdir. Ayyıldız [7], hasarlı kalıp parçalarının tamiri ve üretimi için tersine mühendislik yaklaşımını ele almıştır. Tam ve Chan [19], tersine mühendislik yaklaşımı ile termoform kalıp tasarlamışlardır. Ayrıca, düz ve helis dişli çarklar tersine mühendislik ile BDT modellerinden yola çıkarak tanımlanmıştır [20], [21]. Matta vd. [22], BDT/BDÜ/CAM, hızlı prototipleme ve imalat sistemleri ile ilgili gerçekleștirilen çalışmaları kapsamlı bir şekilde sunmuşlardır. Çetinel [1]'in tersine mühendislik yaklaşımı ise, bir nesnenin 3D modelini oluşturabilmek için fotogrametri yöntemini kullanmayı içermektedir. Salamoun ve Suchy [12], alttan kesmeye maruz kalan ve kalmayan düz ve helis dişli çark yarıçaplarının hesaplanması ve sınır noktalarının belirlenmesi için bir algoritma geliştirmişlerdir. Aziz [23], yaptığı çalışmada, adım, helis açısı diş sayısı ve kalınlığı gibi temel geometrik parametrelerden diş profili oluşturmak ve dişli çarkların üzerindeki bütün noktaları tespit ederek SEM modellerini oluşturmak için yöntemler sunmuştur. Brauer [24], çalışmasında konik evolvent dişli çarkı, üç farklı evolvent dişli ile matematiksel tanımlamıştır. Yang [25], çalışmasında asimetrik helis dişli çarklarının matematiksel modelini, bilgisayar destekli sonlu eleman gerilme analizleri ve alttan kesme analizleri yaparak gerçekleştirmiştir. Rosic [26], evolvent düz dişli çarkların tasarımı için bilgisayar destekli kinematik bir model oluşturarak dişli çarkların optimum ölçülerde imal etmek ve basma/çekme analizlerini yapmak için yardımcı bir yaklaşım geliştirmiştir. Liu vd. [27], hızlı prototipleme ve tersine mühendisliği birleştirmiş ve yeni bir yöntem geliştirmişlerdir. Unigraphics platformu bünyesinde $\mathrm{C}++$ ile geliştirdikleri bu yöntemde, nokta bulutunu iki boyut kesit alarak modelleyip dilimlere ayırmışlardır. İki boyutlu BDT modeli, hızlı prototipleme için dilimlere ayrılmış ve yüzey modelini STL dosyasına çevirmeye gerek duymadan hızlı prototipleme makinesine göndermişlerdir. Kim vd. [28], tersine mühendisliğe yardımcı olabilecek serbest yüzeyli parçaların geometrik özelliklerini tespit edebilen bir sayısallaştırma cihazı tasarlamışlardır. Sayısallaştırma cihazının kullanabillirliğini deneysel olarak kanıtlamışlardır. Galantucci vd. [29], hızlı prototipleme ile tersine mühendislik arasındaki bağlantıya odaklanarak üçgensel ağ örme ve hacimsel yaklaşım işlemi ile bir yöntem geliştirmişlerdir. Mavromihales vd. [30], kiriş havalandırma kanatlarını tersine mühendislik kullanarak yeniden imal etmişlerdir. Chen vd. [33], türbin kanatlarının üç boyutlu geometrik tasarımını yapmak amacıyla tek bir yüzeyde, türbin kanadının modellenmesi ve yüzey sayısallaştırma işlemlerini birleştirmişlerdir. İskender vd. [36] gelişmiş çizilme direncini tespit etmişler ve yüzey modifikasyonunu incelemişlerdir.

\section{Tersine Mühendislik Çalışmalarında Kullanılan Yöntem}

Tersine mühendisliğin makine sektöründeki ihtiyaçlar doğrultusunda kullanılması ile ilgili literatürde mevcut olan Ayyıldız [7] ve Şahin vd. [34] nin yaptığı çalışmalar detaylı olarak ele alınacaktır. Böylece tersine mühendisliğin hangi durumlarda nasıl uygulandığı ve aşamalarının ne olduğunun daha detaylı incelenmesi amaçlanmaktadır. Tersine mühendislikte bir tasarım modeli oluşturmak için öncelikle taranacak model belirlenir. Modelin geometrik özelliklerine uygun tarayıcıyla ölçüm işlemi gerçekleştirildikten sonra BDT modeli elde edilir [31], [32].

Ayyıldız [7], çalışmasında, hasarlı kalıp elemanlarının tamiri amacıyla tersine mühendislik yaklaşımını ele almıştır. Hasarlı kalıp elemanından tarama aleti kullanılarak nokta bulutu formatı oluşturulur ve BDT formatına çevrilir. Gerekli düzenlemeler yapıldıktan sonra BDT modeli haline getirilen ürün bilgisayar destekli üretim/imalat uygulamalarında kolaylıkla kullanılabilir. Şekil 5'de hasarlı kalıp elemanının tamiri için geliştirilen sistemin akış şeması verilmiştir [7], [8]. 


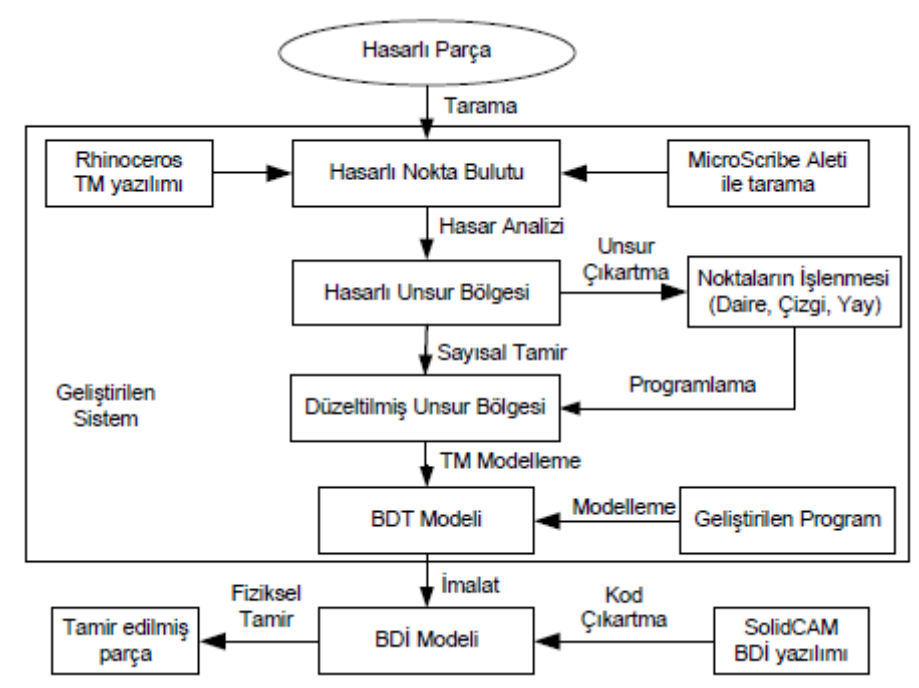

Şekil 5. Hasarlı kalıp elemanının tamiri için geliş̧tirilen sistemin akış şeması [7].

Ayyıldız'ın [7], bu çalışmasında geliştirdiği program Visual Basic programlama dilinde yazılmıştır. BDT sistemi olarak ise Solidworks ve Rhinoceroes paket programları kullanılmışıtır. Visual Basic programlama dilinden Solidworks ve Rhinoceros programlarıyla harekete geçerek bu programların eș zamanlı çalışması sağlanmıştır. Şekil 6'da Rhinoceros programıyla eşzamanlı çalışan Solidworks penceresinin genel bir görünümü verilmiştir [7], [8].

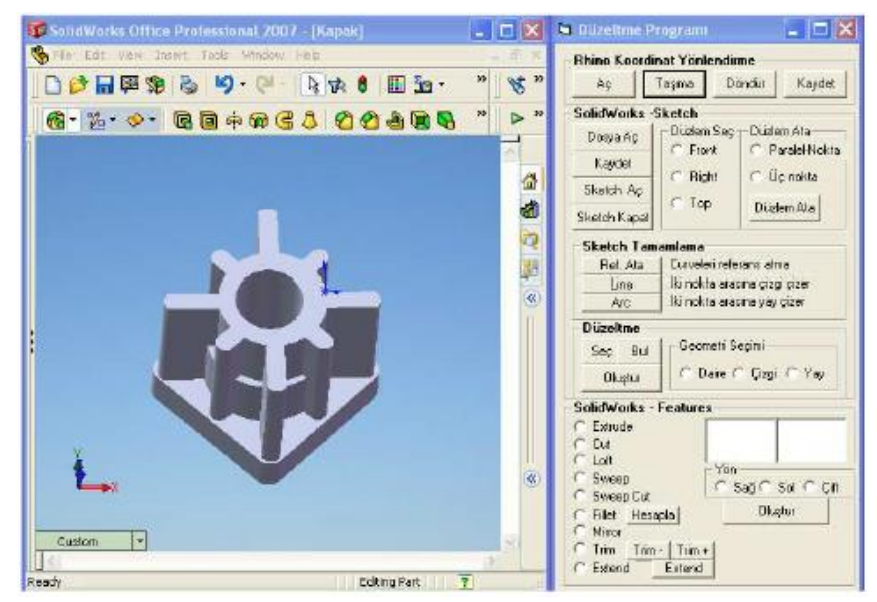

Şekil 6. Rhinoceros programı ile eşzamanlı çalışan Solidworks için örnek arayüz [7].

Geliştirilen sistem, hasarlı bir kalıp elemanı (kalıp lokması) üzerinde uygulama yapılarak açıklanmıştır (Şekil 7).

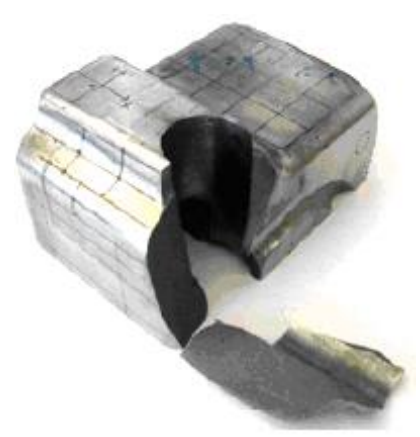

Şekil 7. Hasarlı kalip elemanı [7]. 
Hasarlı parça düz bir zemin üzerine sabitlendikten sonra MicroScribe üç boyutlu tarama cihazı yardımıyla nokta bulutu verisi alınmıştır. Parçanın koordinatları Rhinoceros programı ile alınıp hasarlı parça üzerinden boyut bilgisi elde edilmiştir (Şekil 8).

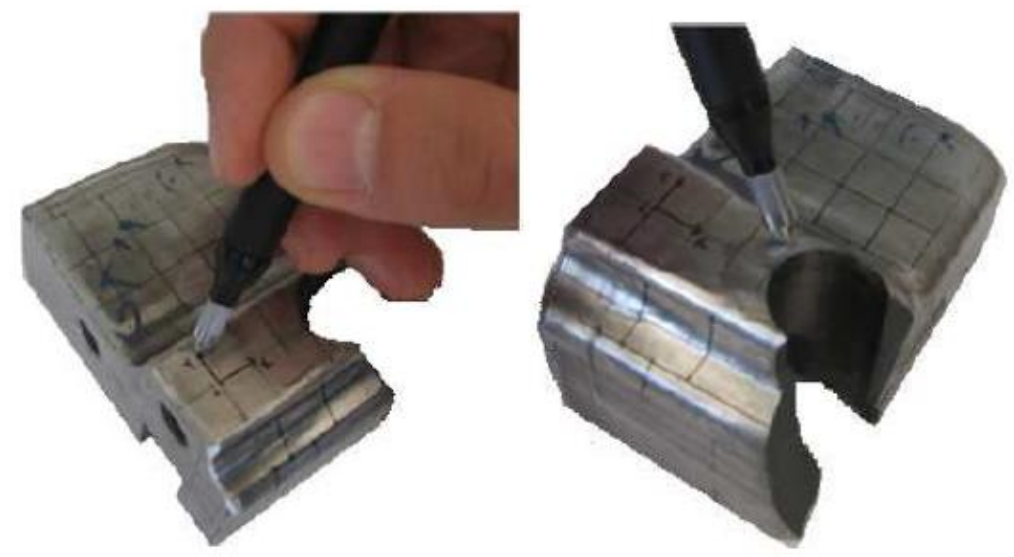

Şekil 8. Parça üzerinden orijin alma ve boyut bilgisi elde etme [7].

Rhinoceros BDT programında parçadan elde edilen boyut bilgisi, nokta bulutu olarak gösterilmiştir (Şekil 9).

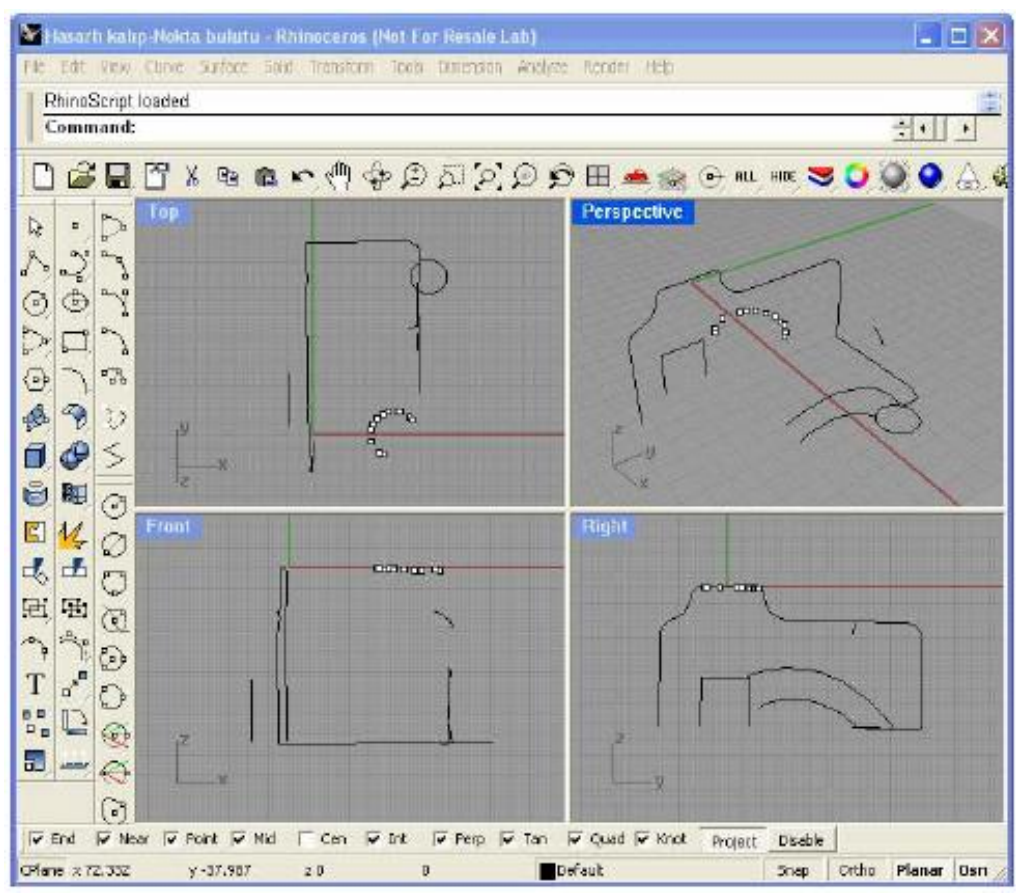

Şekil 9. Rhinoceros BDT programındaki nokta bulutu görüntüsü [7].

Nokta bulutu verisinde orijinin tanıtılmasında oluşabilecek hatalardan dolayı taşıma ve döndürme gibi düzenleme işlemleri gereklidir. Bu düzenlemelerinden ardından kaydedilen nokta bulutu verisi, IGES dosyası olarak Solidworks programına aktarılır. Çizimle ilgili bir dizi düzeltme işleminin ardından hasarlı kalıp elemanının BDÜ verisi son halini alır (Şekil 10). 


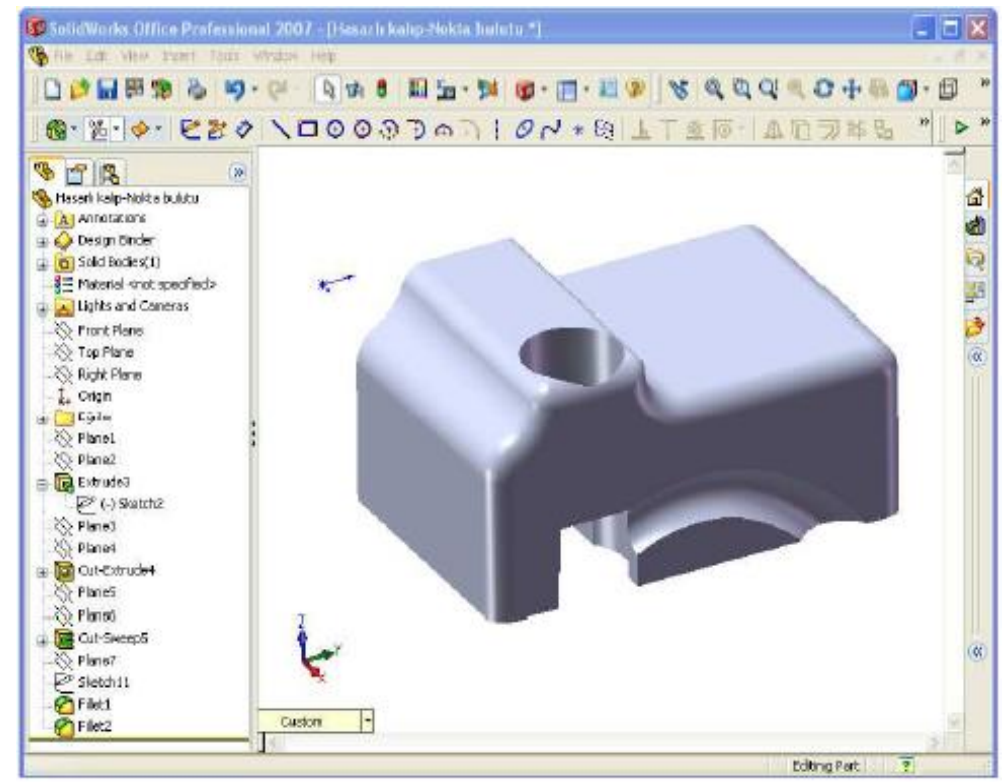

Şekil 10. Hasarlı kalıp elemanının onarımı yapılmış modeli [7].

Hasarlı kalıp elemanının BDT/BDÜ dönüşümü yapılarak G ve M kodları çıkarılır ve uygun talaşlı imalat yöntemiyle ya da hızlı prototipleme ile üretimine geçilir. Böylelikle hasarlı bir kalıp elemanı tersine mühendislik işlemi ile yeniden üretilip kullanılabilir hale getirilmiş̧ir.

Bir başka çalışmada ise; şanzıman mekanizmasında kullanılan deforme olmuş diş profiline sahip bir helis dişlinin, tadilatı yapmak üzere geliştirilen üç boyutlu modelinin tersine mühendislik yaklaşımı ile elde edilmesi anlatılmaktadır. Çalışmada hasarlı dişliye ait veriler üç boyutlu tarayıcı kullanılarak taranmıştır. Tarama işlemi AICON Smart Scan marka tarayıcı ile yapılmıştır (Şekil 11) [34].
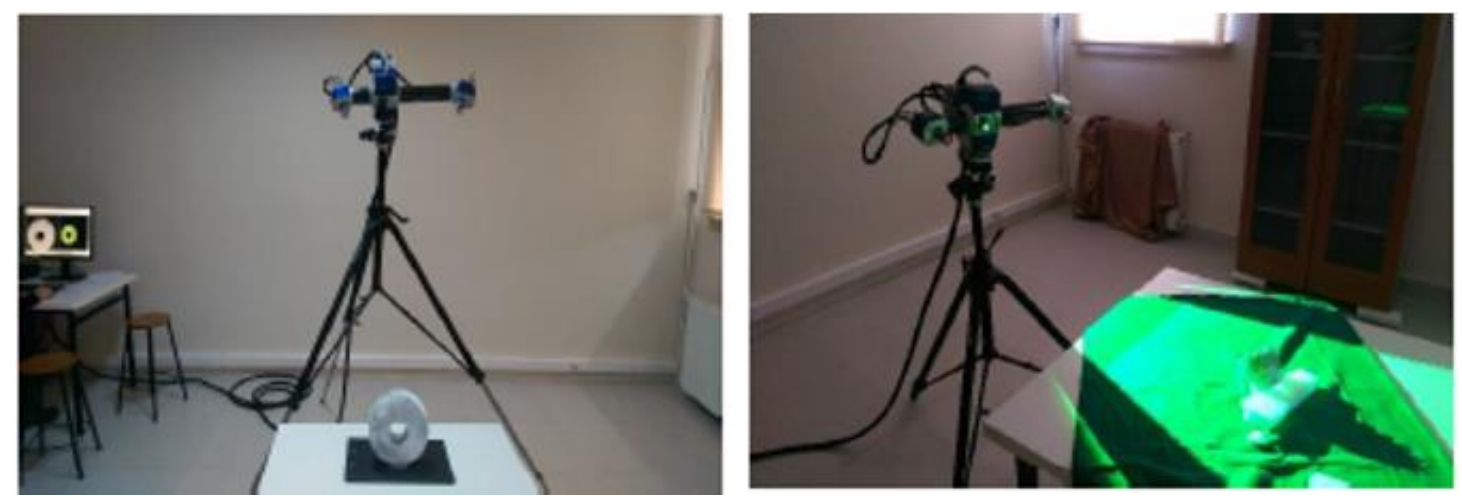

Şekil 11. Tarama işleminden görüntüler [34].

Parça $15-20^{\circ}$ döndürülerek görüntü almaya devam edilmiş ve bu şekilde toplam 20 adet görüntü alınmıştır. Tarama işlemi tamamlandıktan sonra tarayıcının kör noktasında kalan boşluklar doldurulmuş ve görüntü STL formatında kaydedilmiştir. Hasarlı diş profili modelinin oluşturulmasında Geomagic Design $\mathrm{X}$ yazılımı kullanılmıştır. Bu yazılım içine alınan nokta bulutu verisinde 230077 adet nokta sayısı mevcuttur (Şekil 12a). Modelleme yapılabilmesi için nokta bulutu verisinden ağ modeli elde edilmiştir (Şekil 12b) [34], [35]. 


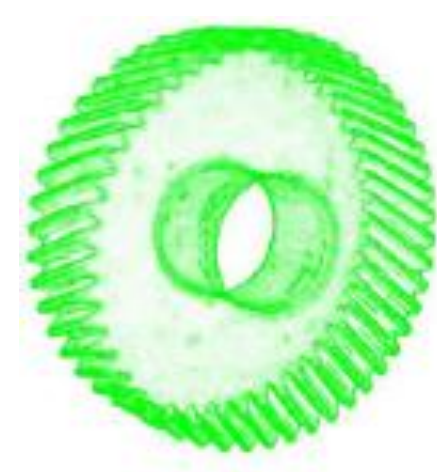

(a)

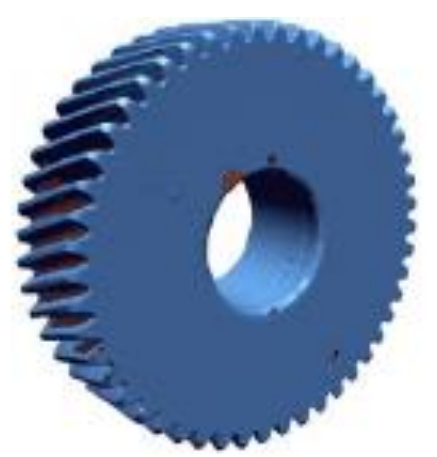

(b)

Şekil 12. Hasarlı dişli: (a) nokta bulutu verisi, (b) ă̆ modeli [34].

Elde edilen üç boyutlu diş profilinde sapma miktarının minimize edilmesi oldukça önemlidir. Sapma analizi yapılarak parça boyutu, çalışma hassasiyeti ve bölgesel kararlılık değişkenleri dikkate alınır. Bütün bu düzenlemelerden sonra hasarlı diş profilinin üç boyutlu modeli elde edilir ve imalat aşamasına geçilir (Şekil 13) [34].

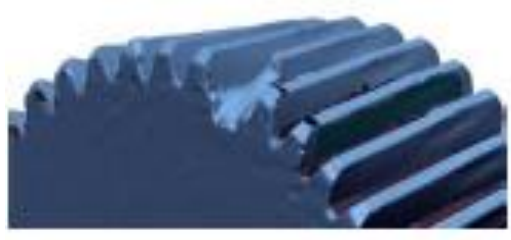

(a)

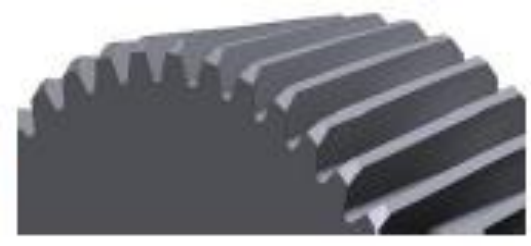

(b)

Şekil 13. (a) Hasarlı diş profili, (b) Onarılmış diş profili [34].

Üç boyutlu modeli oluşturulan heliş dişlinin üretilmesi için hızlı prototipleme yapılmıştır. 3Dison Pro marka yazıcı kullanılmıştır. (Şekil 14) [34].

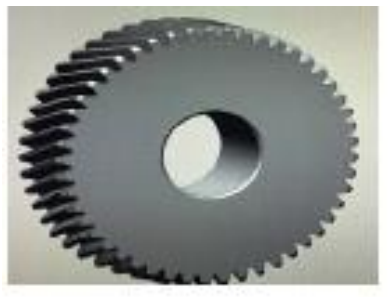

(a)

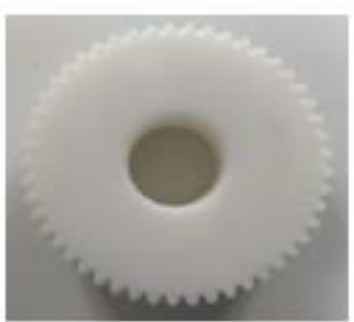

(c)

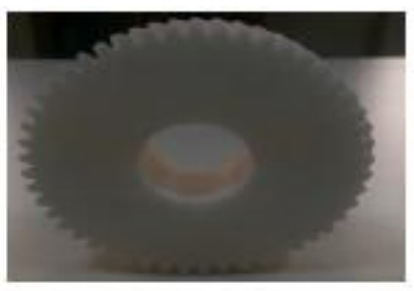

(b)

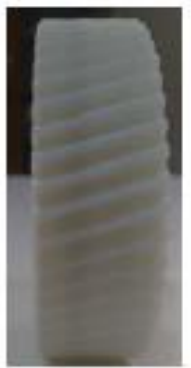

(d)

Şekil 14. BDT Modeli oluşturulan dişli ve dişili çıktıları [34]. 


\section{4. İrdelenen Çalışma Sayısı}

$\mathrm{Bu}$ derleme çalışmasında, tersine mühendislik ile ilgili literatürde mevcut olan birçok çalışma incelenmiştir. Çalışma kapsamında araştırma ve derleme makaleleri, yüksek lisans ve doktora tez çalışmaları gibi akademik çalışmaların yanında bu alanda hazırlanan proje, sunum ve raporlara da ulaşılmaya çalışılmıştır. Araştırma kapsamında tersine mühendislik ve uygulamaları ile ilgili, araştırma makaleleri, derlemeler, sunumlar, yüksek lisans ve doktora tezleri olmak üzere toplam 40 kadar çalışma incelenmiştir. $\mathrm{Bu}$ derlemede faydalanılan çalışmaların dağılımları Çizelge-1 de sayısal olarak ifade edilmiştir.

Çizelge 1. Tersine Mühendislik ile ilgili incelenen toplam çalışma saylst.

\begin{tabular}{lrr}
\hline Çalışmanın tipi & Sayı & $\%$ \\
\hline Doktora tezi & 2 & 5 \\
Yüksek lisans tezi & 7 & 17,5 \\
Araştırma makalesi & 20 & 50 \\
Derleme makalesi & 4 & 10 \\
Proje & 1 & 2,5 \\
Rapor & 1 & 2,5 \\
Sunum & 1 & 2,5 \\
Diğerleri & 4 & 10 \\
Toplam & 40 & 100 \\
\hline
\end{tabular}

Tersine mühendislik yazılımının kullanımı, teknolojinin de gelişmesiyle her geçen gün artmaktadır. Dolayısıyla literatürde bu konuyla ilgili birçok çalışma mevcuttur. Bu çalışmada sadece tersine mühendisliğin makine mühendisliği alanındaki uygulamaları incelenmiş, tersine mühendislik süreci ile ilgili bilgi verilmiş ve hangi durumlarda tersine mühendislik işlemine ihtiyaç duyulduğu açıklanmıştır.

\section{Sonuçlar ve Tartışma}

$\mathrm{Bu}$ derleme kapsamında Tersine mühendisliğin, Makine mühendisliği alanında uygulamaları incelenmiş, tersine mühendisliğin aşamaları hakkında detaylı bilgi verilmiştir. Tersine mühendislikte temel amaç, mevcut üründen yola çıkarak BDT modelinin elde edilmesidir. BDT modeli elde edilen ürün, yeniden kolaylıkla üretilebilmektedir. Makine sektöründe tersine mühendislik ihtiyacı genellikle, deforme olmuş bir malzemenin tadilatında ya da geliştirilmek / yeniden üretilmek istenilen eksik dokümantasyona sahip bir malzemenin üretiminde ortaya çıkmaktadır. Buna benzer durumlarda literatürde de görüldüğü üzere, tersine mühendislik süreci oldukça tercih edilen verimli bir yoldur.

\section{Kaynaklar}

[1] M. Çetinel, "Tersine mühendislik ile üç boyutlu cisimlerden grafik tasarım için veri eldesi”, Yüksek Lisans Tezi, Yıldız Teknik Üniversitesi Fen Bilimleri Enstitüsü, İstanbul, 124, 2008.

[2] A. Önçağ, H. Tosun, "İzmir universiade oyunları maskot heykelinin tersine mühendislik yöntemleri ile dijitalleştirilmesi ve küçük ölçekli olarak üç boyutlu yazıcı ile imalatı," Soma Meslek Yüksekokulu Teknik Bilimler Dergisi, 2(26), 1-10, 2018.

[3] E. Günpınar, "Tersine mühendislik yoluyla üç boyutlu geometrik modelin oluşturulması ve gemi yapım endüstrisindeki bazı uygulamaları", Dokuz Eylül Üniversitesi Mühendislik Fakültesi Fen ve Mühendislik Dergisi, 18(54), 624-639, 2016. 
[4] F. İşbilir, B. Çelik, A. Özsan, M. Kaynak, "Tersine mühendislik temelli araç üst yapı tasarım, analiz ve üretiminin incelenmesi”, Sürdürülebilir Mühendislik Uygulamaları ve Teknolojik Gelişmeler Dergisi, 1(2), 72-79, 2018.

[5] A. Önçağ, Ç. Tekcan, H. Özden, "Mekanik parçaların tersine mühendislik ile modellenmesinin değerlendirilmesi ve bir uygulama. Pamukkale Üniversitesi Mühendislik Bilimleri Dergisi, 24(1), 4349, 2018.

[6] H. Demir, "Cad datası olmayan parçaların tersine mühendislik metodu ile cad datalarının oluşturulması", Yüksek Lisans Tezi, Fırat Üniversitesi Fen Bilimleri Enstitüsü, Elazığ, 97, 2018.

[7] M. Ayyıldız, "Hasarlı makine elemanlarının tersine mühendislikle ile tasarım ve imalat için yenilenmesi”, Yüksek Lisans Tezi, Karabük Üniversitesi Fen Bilimleri Enstitüsü, Karabük, 106, 2009.

[8] M. Ayyıldız, C. Göloğlu, C., "Hasarlı kalıp elemanlarının tamiri için tersine mühendislik destekli bir çerçeve çalışması", 5. Uluslararası İleri Teknolojiler Sempozyumu, Iats, Karabük, Mayıs 13-15, 14371441, 2009.

[9] J. P. Kruth and A. Kerstens "Reverse engineering modeling of-free-form surfaces from point cloud subject to boundary conditions", Journal of Materials Processing Technology, 76, 120-127, 1998.

[10] K. Nitish, H. Kumar, J. S. Khurmi, "Experimental Investigation of Process Parameters for Rapid Prototyping Technique (Selective Laser Sintering) to Enhance the Part Quality of Prototype by Taguchi Method”, Procedia Technology, vol. 23, Pages 352-360, 2016.

[11] Y. Jun, V. Raja, S. Park, "Geometric Feature Recognition for Reverse Engineering using Neural Networks", International Journal of Advanced Manufacturing Technology, 17, 462-470, 2001.

[12] C. Salamoun, M. Suchy, "Computation of helical or spur gear fillets," Mechanism and Machine Theory 8(3), 305-322, 1973.

[13] N. Sherry, "Reverse engineering of automotive parts applying laser scanning and structured light techniques" The University of Tennessee, Knoxville, 2005.

[14] T. Türkücü, H. Börklü, "Tersine mühendislik yaklaşımına dayalı yeni bir imalat için tasarım işlem modeli”, Gazi Üniversitesi Fen Bilimleri Dergisi Part C: Tasarım ve Teknoloji, 6(1), 91-104, 2018.

[15] G. Berbercuma, "Üç boyutlu tarayıcılar ile veri toplanması ve CAD ortamına değişik formatlarda aktarılması”, T.C. Gebze Yüksek Teknoloji Enstitüsü, Mühendislik ve Fen Bilimleri Enstitüsü, Yüksek Lisans Tezi, Gebze, 258, 2006.

[16] M. Paulic, T. Irgolic, J. Balic, F. Cus, A. Cupar, T. Brajlih, I. Drstvensek, "Reverse Engineering of Parts with Optical Scanning and Addictive Manufacturing" 24th DAAAM International Symposium on Intelligent Manufacturing and Automation. ScienceDirect, Procedia Engineering, 69, 795-803, 2014.

[17] I. Budak, J. Hodolic, M. Sokovic, "Development of a programme system for datapoint pre-processing in Reverse Engineering”, Journal of Materials Processing Technology 162-163, 730-735, 2005.

[18] M. Sokovic and J. Kopac, RE (reverse engineering) as necessary phase by, journal of materials processing technology, Faculty of Mechanical Engineering, University of Ljubljana, Slovenia, 398403, 2006.

[19] K. W. Tam, K.W. Chan, "Thermoforming mould design using a reverse engineering approach", Robotics and Computer-Integrated Manufacturing 23, 305-314, 2009.

[20] M. Ayyıldız, A. Çiçek, "Düz Dişli Tasarımında Bir Tersine Mühendislik Uygulaması", Sakarya University Journal of Science, 14(1), 39-44, 2010.

[21] A. Çiçek, "Dişlilerin uzman sistem tabanlı tanımlanması ve detaylı boyutlarının çıarılması", Gazi Üniversitesi Mühendislik ve Mimarllk Fakültesi Dergisi, 23(3), 709-717, 2008.

[22] A. K. Matta, D. R. Raju, K. N. S. Suman, "The Integration of CAD/CAM and Rapid Prototyping in Product Development", A Review, Materialstoday: Proceedings, 2, 3438-3445, 2015.

[23] E. S. Aziz, "Knowledge-Based Geometry Generation for Spur and Helical Gears." Concurrent Engineering, 10(3), 251-261, 2002. 
[24] J. Brauer, "A general finite element model of involute gears," Finite Elements in Analysis and Design, 40, 1857-1872, 2004.

[25] S. C. Yang, "Mathematical Model of a Helical gear with asymmetric involute teeth and its analysis", International Journal Advanced Manufacturing Technology, 26, 448-456, 2005.

[26] B. Rosic, "Design and simulation of meshing of internal involute spur gears with pinion cutters", Facta Universitatis Series: Mechanical Engineering, 1(9), 1193-1198, 2002.

[27] G. Liu, Y. Wong, Y. Zhang, H. Loh, "Modelling cloud data for prototype manufacturing," Journal of Materials Processing Technology, 138, 53-57, 2003.

[28] S. Kim, Y. Choi, J. Oh, "Reverse engineering: high speed digitization of free-form surfaces by phaseshifting grating projection moire topography," International Journal of Machine Tools \& Manufacture, 39, 389-401, 1999.

[29] L. Galantucci, G. Percoco, U. Dal Maso, "A volumetric approach for STL generation from 3D scanned products", Journal of materials processing technology, 204, 403-411, 2008.

[30] M. Mavromihales, J. Mason, W. Weston, "A case of reverse engineering fort he manufacture of wide chord fan blades (WCFB) used in Rolls Royce aero engines", Journal of Materials Processing Technology, 134: 179-286, 2003.

[31] C. Moenning, N. Dodgson, "A new point cloud simplification algorithm", Presented at 3rd IASTED International Conference on Visualization, Imaging and Image Processing, Spain, 1-6, 2003.

[32] J. K. Ruan, Y. L. Ke, S. Q. Fan, H. Y. Dong, "Research on rapid repairing techniques for auto panel dies”, Journal of Materials Processing Technology, 187-188: 69-72, 2007.

[33] L. Chen, G. Lin, "Reverse engineering in the design of turbine blades- a case study in applying the MAMD”, Robotics and Computer Integrated Manufacturing, 16, 161-167, 2000.

[34] İ. Şahin, T. Şahin, H. Gökçe, O. Eren, "Hasarlı dişlilerin tersine mühendislik yaklaşımıyla yeniden oluşturulması”, Düzce Bilim ve Teknoloji Dergisi, 5, 485-495, 2017.

[35] P. Ratnadeep, A. Sam "A new Steiner patch based file format for Additive Manufacturing processes" Computer-Aided Design, Volume 63, Pages 86-100, 2015.

[36] Ş. İskender, S. Işmar, A. Evcin "Surface modification of PC and PMMA sheet for enhanhed scratch resistance", Journal of Characterization”, 1(3) 131-136, 2021. 